\title{
23-gauge pars plana vitrectomy for management of posteriorly dislocated crystalline lens
}

This article was published in the following Dove Press journal:

Clinical Ophthalmology

7 December 2011

Number of times this article has been viewed

\author{
Minhee Cho \\ RV Paul Chan \\ Weill Cornell Medical College, \\ Department of Ophthalmology, \\ New York, NY, USA
}

Correspondence: RV Paul Chan Weill Cornell Medical College,

Department of Ophthalmology, I 305 York Ave, I I th Floor, New York, NY I002I, USA

Tel +l 6469622540

$\mathrm{Fax}+\mathrm{I} 6469620602$

Email roc90।3@med.cornell.edu
Purpose: Management of posteriorly dislocated crystalline lens has traditionally been performed with a standard 20-gauge vitrectomy system. This study demonstrates the use of a 23-gauge vitrectomy system for removal of retained lens fragments secondary to spontaneous dislocation or complicated cataract extraction.

Methods: A retrospective, noncomparative, interventional consecutive case series at a single university medical center.

Results: Fourteen eyes of 14 patients underwent a 23-gauge vitrectomy for removal of retained lens. Mean age was 75 years. Mean logMAR (logarithm of minimum angle of resolution) visual acuity was 1.47 (Snellen equivalent 20/600) preoperatively and 0.37 (Snellen equivalent 20/50) postoperatively. A 20 -gauge fragmatome was used in $64 \%$ of cases. The mean time to the best post-vitrectomy acuity was 4.9 weeks. The mean healing time was 25 days (6-48 days). Post-vitrectomy complications included choroidal detachment (two patients), vitreous hemorrhage (two patients), and acute ocular hypertension (two patients). The mean length of follow-up was 6.2 months (1-13 months).

Conclusion: A 23-gauge vitrectomy system alone or in combination with the 20-gauge fragmatome is a safe and efficacious option for removal of dense posteriorly dislocated crystalline lens material.

Keywords: lensectomy, retained lens, PPV

\section{Introduction}

Micro-incision vitrectomy surgeries using either 23- or 25-gauge systems have become widely popular since their introduction in early to mid-2000s. Unlike the traditional 20 -gauge system, the instruments are introduced through trocars placed in a transconjunctival sutureless manner. As a result of continued improvements in small-gauge instrumentation, the spectrum of complex vitreoretinal maneuvers feasible with 23- or 25-gauge systems has expanded in recent years. One such area includes removal of posteriorly dislocated crystalline lens. In the age of clear-corneal incision cataract extraction, the rate of this complication ranges from $0.3 \%$ to $1.1 \%{ }^{1}$ posterior capsular rupture during phacoemulsification is the most frequent reason. ${ }^{2}$ Ocular trauma and connective tissue diseases such as Marfan's syndrome and Ehlers-Danlos syndrome can also lead to spontaneous dislocation of the crystalline lens.

Pars plana lensectomy for retained lens fragments has most commonly been reported with the use of traditional 20-gauge vitrectomy systems. ${ }^{2-10}$ A 20-gauge vitrectomy, however, most often requires a conjunctival peritomy, a larger sclerotomy, and sutureclosure of the wounds, leading to longer operative and healing time, postoperative 
discomfort, and refractive changes. ${ }^{1-13}$ Decreased healing and operative time, faster visual recovery, and reduced postoperative inflammation illustrate the benefits of smallergauge vitrectomy systems. ${ }^{14-18}$ Ho et al reported the use of the 25-gauge vitrectomy system for the management of retained lens materials and demonstrated an excellent visual outcome with no complications. ${ }^{19}$ The main difference between the early generation 25-gauge and 23-gauge systems is the greater stiffness and fluidics of 23-gauge that mirror 20-gauge, leading to preference for the 23-gauge system by some surgeons for cases anticipated to be more complex. This report reviews the use of the 23-gauge system for the management of dislocated lens material. This is the first consecutive series of eyes managed with 23-gauge pars plana vitrectomy (PPV) for removal of posteriorly dislocated lens material secondary to spontaneous dislocation or complicated cataract extraction.

\section{Methods}

This is a retrospective, noncomparative, interventional consecutive case series at a single medical center. Medical records of consecutive patients who underwent a 23-gauge PPV for dislocated lens material by a single surgeon (RVPC) at Weill Cornell Eye Associates from January 2006 to June 2010 were reviewed. The study protocol was approved by the Institutional Review Board. All patients had a minimum postoperative follow-up of 1 month. Medical records were reviewed for demographic information, pre-existing eye conditions, prior ocular surgeries, initial and final visual acuity, intraoperative procedures and findings, and postoperative complications. Hypotony was defined as intraocular pressure (IOP) less than or equal to $5 \mathrm{mmHg}$. Patients were referred to the vitreoretinal surgeon for spontaneously dislocated crystalline lens or after complicated cataract surgery; the timing of PPV was left up to the discretion of the vitreoretinal and anterior segment surgeon. Indications for surgery included retained nuclear material or cortex with or without marked intraocular inflammation, uncontrolled IOP, and cystoid macular edema. Preoperative characteristics of the patients are summarized in Table 1. Snellen best-corrected visual acuity (BCVA) was converted to the logarithm of minimum angle of resolution (logMAR) for statistical analysis. Two-tailed $t$-test was used to analyze the relationships between different variables.

All surgical procedures were performed using a threeport transconjunctival mirocannula-based 23-gauge PPV system (Accurus Vitrectomy System, Alcon Laboratories Inc, Fort Worth, TX). If a dense retained nucleus was anticipated, limited conjunctival peritomy was performed in preparation for the enlargement of the sclerotomy with a 20-gauge microvitreoretinal (MVR) blade to fit the fragmatome handpiece (Alcon Laboratories Inc). Removal of the lens using the vitrectomy cutter handpiece was always attempted first with proportional vacuum setting at maximum cut rate of 1500 cuts/minute and vacuum of $400 \mathrm{mmHg}$. If the lens encountered was dense, the cut rate was decreased to 1000 cuts/minute and vacuum increased up to $600 \mathrm{mmHg}$. The decision to use perfluorocarbon liquid or 20-gauge fragmatome was made intraoperatively, depending on the density and size of the lens material. When only the vitrector was used to remove the lens material, a bimanual technique was used in which the light pipe guided the lens material into the vitreous cutter port. At the end of every case, each microcannula was removed and the wounds were examined and sutured with 7-0 vicryl sutures if leakage was present. If the fragmatome was used, the 20-gauge sclerotomy created in the superotemporal quadrant was closed with 7-0 vicryl suture. All patients were examined on postoperative day 1 and at various times after depending on patients' recovery until at least 4 weeks postoperatively. Patients were monitored for complications including wound leak, hemorrhage, retinal tears or detachments, hypotony, glaucoma, choroidal detachment, endophthalmitis, and cystoid macular edema.

\section{Results}

Fourteen eyes of 14 consecutive patients with dislocated lens material managed with 23-gauge PPV system were included in the study. There were nine women (64\%) and five men $(36 \%)$, with a mean age of $75 \pm 3$ years (range $48-96$ years). Eleven patients $(79 \%)$ underwent cataract extraction with phacoemulsification by anterior segment surgeons. Three patients $(21 \%)$ presented with a complete dislocation of the crystalline lens (two due to trauma, one due to Marfan's syndrome) and underwent planned pars plana lensectomy. The pre-cataract extraction mean $\log$ MAR visual acuity was $1.3 \pm 0.2$ (20/400 Snellen equivalent, range 20/40 to light perception vision). The density of the nuclear cataract ranged from grade 2 to mature white cataract (Table 1). Mature cataract defined as nuclear sclerosis of grade 3 or more were seen in $71 \%$ of the patients. The mechanism of posterior dislocation of lens material during cataract extraction included posterior capsule tear (73\%) and zonular dehiscence (27\%). Four patients (29\%) had pseudoexfoliation syndrome.

Ninety-one percent (ten out of eleven) of patients who underwent a planned phacoemulsification procedure received an intraocular lens (IOL) implant at the end of the procedure. 


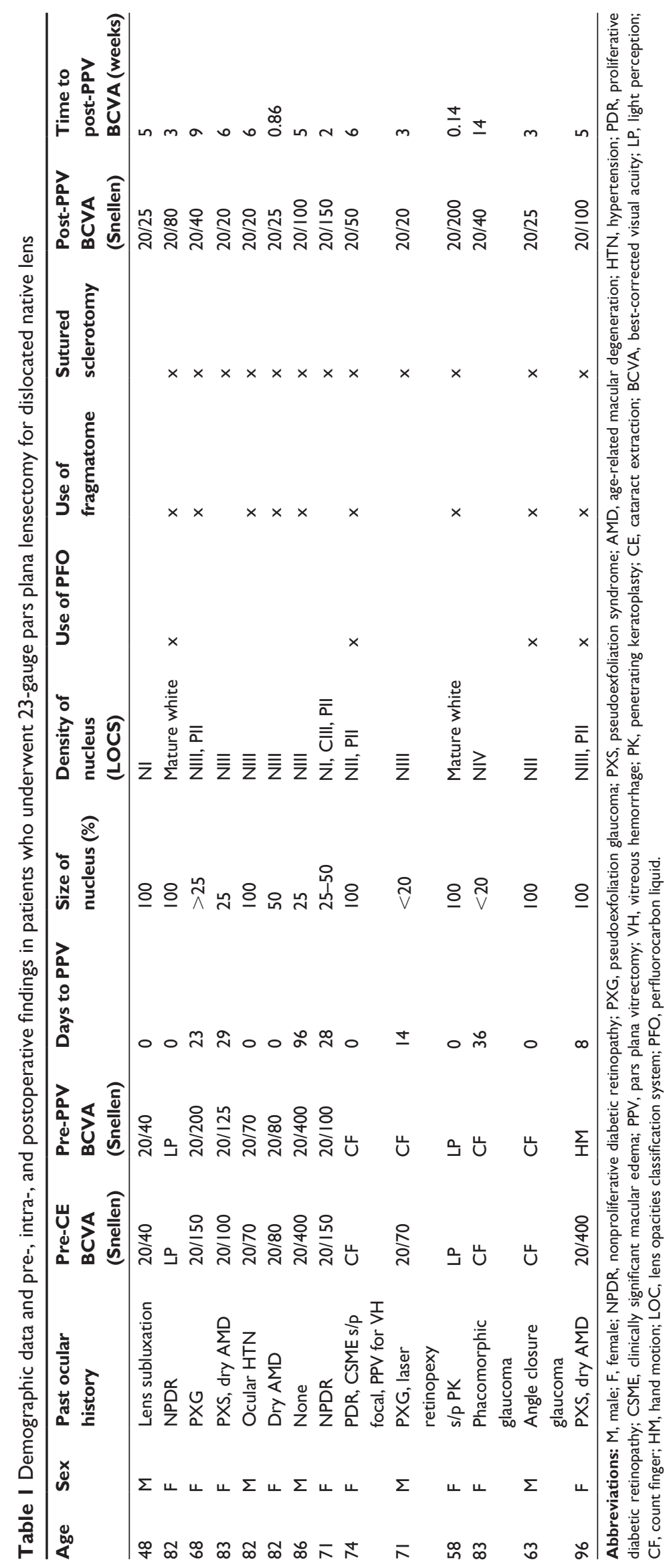


Seventy-five percent (six out of eight) of the patients without concurrently planned PPV underwent anterior vitrectomy by the anterior segment surgeon prior to the placement of the IOL. Out of four patients (29\%) without IOL implantation prior to vitrectomy, one was left aphakic, two received anterior chamber IOL, and one received iris-sutured IOL. Four of eleven patients who had complicated phacoemulsification $(36 \%)$ were referred on the day of cataract extraction and underwent immediate PPV. Among those patients who had delayed vitrectomy after complicated cataract extraction, the time to PPV ranged from 8 days to 3 months (average $33 \pm 11$ days). The reasons for this delay included corneal edema (86\%), choroidal effusion (14\%), and persistent inflammation (14\%).

Demographic, pre-, intra-, and postoperative characteristics of the patients are listed in Table 1. The pre-PPV mean $\log$ MAR vision was $1.4 \pm 0.2$ (20/500 Snellen equivalent, range 20/100 to hand motion vision). The pre-PPV mean IOP was $20.6 \pm 4.4 \mathrm{mmHg}$ (range 10-38 $\mathrm{mmHg}$ ). Transconjunctival beveled 23 -gauge incision was made in $71 \%$ of cases. Twelve patients $(86 \%)$ had dislocated lens material that included at least $25 \%$ of the nucleus. Perfluorocarbon heavy liquid was utilized in $29 \%$ of cases to reduce the impact of lens materials falling on the macular surface during removal. A 20 -gauge fragmatome was used in $64 \%$ of cases. Seventyeight percent of those cases where fragmatome was utilized had dense mature lens fragments (grade 3 or above). No tears or holes were noted in the retinal periphery at the end of each case. One or more of the sclerotomies were closed in $86 \%$ of cases.

On postoperative day 1 , one patient $(7 \%)$ had a postoperative hypotony (IOP 2). The mean IOP was $16 \pm 2.4 \mathrm{mmHg}$ (range $2-32 \mathrm{mmHg}$ ). The mean post-PPV BCVA on postoperative day 1 was $1.5 \pm 0.19$ (Snellen equivalent 20/500, range $20 / 50$ to hand motion vision). The mean post-PPV BCVA was $0.37 \pm 0.09$ (20/50 Snellen equivalent, range $20 / 20$ to $20 / 200$ ). The difference between pre-PPV visual acuity and post-PPV BCVA was statistically significant (20/500 vs $20 / 50, P=0.0002)$. Fifty-seven percent of the patients had better than $20 / 40$ vision. Mean time to the best post-PPV acuity was $4.9 \pm 0.9$ weeks (range 1 day-14 weeks). Mean healing time defined as presence of only trace inflammation in the anterior chamber and/or start of tapering of prednisolone drops was $25 \pm 3$ days (range 6-48 days). Closure of scleromities with sutures was not associated with the length of healing time $(P=0.97)$ or the time to postoperative BCVA $(P=0.45)$ (Table 2$)$. The use of fragmatome, the size of retained nucleus, and the timing of PPV also did not
Table 2 Factors affecting the healing time and the time to postoperative best-corrected visual acuity

\begin{tabular}{lll}
\hline & $\begin{array}{l}\text { Healing time } \\
\text { (days) }(\mathbf{n})\end{array}$ & $\begin{array}{l}\text { Time to BCVA } \\
\text { (days) }\end{array}$ \\
\hline Sutured sclerotomy & $24.8(I 2)$ & $4.1(12)$ \\
Sutureless sclerotomy & $24(2)$ & $9.5(2)$ \\
& $P=0.97$ & $P=0.45$ \\
Fragmatome & $21.3(9)$ & $4.22(9)$ \\
No fragmatome & $30.8(5)$ & $6(5)$ \\
& $P=0.24$ & $P=0.47$ \\
$<25 \%$ retained nucleus & $18.5(2)$ & $8.5(2)$ \\
$\geq 25 \%$ retained nucleus & $25.8(I 2)$ & $4.3(12)$ \\
& $P=0.63$ & $P=0.58$ \\
Same day PPV & & $3.4(7)$ \\
Delayed PPV & & $6.3(7)$ \\
& & $P=0.14$ \\
\hline
\end{tabular}

Abbreviation: PPV, pars plana vitrectomy.

have any significant association with the length of healing time or time to post-PPV BCVA (Table 2). The difference in the mean post-PPV BCVA did not reach statistical significance whether the PPV was performed immediately or delayed (logMAR visual acuity 0.33 vs $0.41, P=0.67$ ).

Post-vitrectomy complications included choroidal detachment in two patients (one of two had choroidal detachment pre-vitrectomy as a result of complicated cataract extraction), vitreous hemorrhage (two patients), progression of diabetic macular edema (two patients), and ocular hypertension (two patients, one of which was due to nonfunctioning valve in a glaucoma patient) (Table 3). Both patients who developed choroidal detachment on the first postoperative day had sutured sclerotomies. There were no cases of endophthalmitis or retinal tears/detachment. The post-PPV BCVA at the final follow-up was $0.69 \pm 0.3$ (20/100 Snellen equivalent, range $20 / 20$ to no light perception). The average IOP at the final follow-up was $15 \pm 9 \mathrm{mmHg}$ (range 6-43 $\mathrm{mmHg}$ ). Considering all patients including those who developed such complications as neovascular glaucoma from central retinal vein occlusion (final vision light perception) and end-stage glaucoma after keratoprosthesis for corneal perforation (final vision no light perception) unrelated to the vitrectomy

Table 3 Reason for reduced vision after 23-gauge pars plana vitrectomy for dislocated lens material $(n=$ number of patients)

\begin{tabular}{lll}
\hline Cause & $\begin{array}{l}\text { Vision 20/20 } \\
\text { to 20/200 }\end{array}$ & $\begin{array}{l}\text { Vision worse than } \\
\mathbf{2 0 / 2 0 0}\end{array}$ \\
\hline $\begin{array}{l}\text { Vitreous hemorrhage } \\
\text { Choroidal detachment }\end{array}$ & $\mathrm{I}$ & $\mathrm{I}$ \\
$\begin{array}{l}\text { Progression of glaucoma } \\
\text { Progression of diabetic }\end{array}$ & $\mathrm{I}$ & 2 \\
macular edema & 2 & \\
\hline
\end{tabular}


procedure, $50 \%$ of the patients achieved better than 20/40 vision. Excluding these patients, the mean post-PPV final BCVA was $0.33 \pm 0.08$ (Snellen equivalent 20/43). The mean follow-up was $6.2 \pm 1.0$ months (range 1-13 months).

\section{Discussion}

This report demonstrates the utility of 23-gauge vitrectomy system in the management of posteriorly dislocated lens material. It also shows the feasibility and simplicity of combining a 20-gauge instrument (fragmatome) with the 23 -gauge system. Most patients in the study had a dense lens nucleus (71\%), which consequently led to the significant usage of the fragmatome (64\%) and sutured sclerotomy sites (86\%). Despite these additional steps, most patients achieved an excellent visual outcome with low complication rates.

More than $50 \%$ of the patients in this study achieved a final visual acuity of 20/40 or better, with a low complication rate. The mean post-PPV BCVA was 0.37 (20/50 Snellen equivalent). This is comparable to previous reports of lensectomies performed with conventional 20-gauge vitrectomy instruments which demonstrated final visual acuity outcomes of $20 / 40$ or better in $44 \%-71 \% .^{7-9}$ Reports on the exact length of time to post-lensectomy BCVA or healing with either the traditional or small-gauge systems are lacking. Time to healing is a concept that is not universally defined and therefore difficult to measure and compare with other reports. In this present study, the mean healing time defined as presence of only trace inflammation in the anterior chamber and/or start of tapering of prednisolone drops was 25 days (range 6-48 days). Mean time to the best post-PPV acuity was 4.9 weeks (range 1 day-14 weeks).

In all of the patients in this study, the lens removal was attempted first with the 23-gauge vitrector. When the lens fragment was found to be too dense, the 23-gauge sclerotomy was enlarged and the 20-gauge fragmatome was used. In this study, the fragmatome was employed in the majority of cases (64\%). The high number of mature lens (71\%) accounted for the inadequacy of only using the 23 -gauge cutter. Perfluorocarbon liquid was used in $29 \%$ of cases. In studies using the 20-gauge vitrector, the rate of ultrasound fragmentation $(34 \%-76 \%)$ and heavy liquid $(6 \%-13 \%)$ usage varied widely. ${ }^{6,10}$ A small interventional case series by Kongsap demonstrated the use of 23-gauge vitrectomy combined with 20-gauge fragmatome in post-trauma patients and reported excellent visual outcome and safety. ${ }^{20} \mathrm{Ho}$ et al reported the use of the 25-gauge vitrectomy system to remove dislocated lens material without the use of fragmatome or the need for suture closure of any of the sclerotomies. ${ }^{19}$ The use of ultrasound fragmentation or perfluorocarbon liquid at the time of PPV has not been found to statistically affect visual acuity outcomes or rate of retinal detachment. ${ }^{7-10}$ Similarly in this present report, the use of fragmatome or heavy liquid was not associated with the time to post-PPV BCVA or healing time. If the vitrector cutter is inadequate for removing the lens with efficiency due to density of the lens, it is advised to utilize the fragmatome.

Compared with the conventional 20-gauge vitrectomy, the aspiration and infusion rate through the 23 -gauge instruments will inevitably be lower due to smaller port size and narrower inner diameter of the vitrector handpiece. For instance, the 25 -gauge vitrector has a lower aspiration rate by a factor of 6.6 compared with the 20 -gauge cutter; the infusion rate in the 25 -gauge system is decreased by a factor of 6.9. ${ }^{21}$ Despite the difference in the instrument design, combining the 20 -gauge fragmatome with the 23-gauge infusion system did not lead to an appreciable imbalance between aspiration from the fragmatome and inflow from the 23-gauge infusion line. This was partially avoided by raising the infusion pressure. There was no incidence of intraoperative hypotony leading to choroidal effusion in any of the combined cases.

The rate of sclerotomy suturing in this report was $86 \%$. This was due to the high rate of fragmatome use which requires enlarging 23-gauge wound with a 20-gauge MVR blade in order to fit the instrument. The 2010 Preferences and Trends (PAT) survey performed by the American Society of Retina Specialists showed that only $9 \%$ of the surgeons never suture the 23-gauge sclerotomy sites (www.asrs. org). Ninety-one percent of those surveyed who routinely use 23-gauge vitrectomy systems reported suturing one or more of the sclerotomies. Although the suturing rate in this present study was higher than what has been published in the literature for 23-gauge vitrectomy, ${ }^{22}$ this was consistent with having to enlarge one of the wounds with a 20 -gauge MVR blade. In the current study, the suturing of sclerotomy sites was not associated with time to best post-PPV BCVA or the healing time.

This study was not a randomized head-to-head comparative study of the conventional 20 -gauge system versus 23 -gauge system for the removal of retained lens. Therefore, the advantages of using the 23 -gauge system, such as faster healing time, increased patient comfort, decreased operative time, and faster visual recovery cannot be demonstrated directly. The 23-gauge vitrectomy can, however, decrease operative time despite the need for suture closure, and recent literature has clearly established the advantages of the smallergauge systems compared with the conventional system. ${ }^{14-17,23}$ 
Between the two small-gauge systems (25-gauge and 23-gauge), some surgeons may even find the 23-gauge system more effective than the conventional 25-gauge system in performing complex vitreoretinal maneuvers due to greater stiffness of the 23-gauge instruments. Management of a posteriorly dislocated lens requires removal of the lens material while avoiding vitreous traction and retinal injury. This can be safely achieved with the 23-gauge vitrectomy system as demonstrated by the present study.

Many studies employing the conventional 20-gauge system have demonstrated that the timing of vitrectomy after the lens dislocation does not affect the final visual outcome, although lensectomy within 1-4 weeks trended towards a better visual outcome..$^{3-5,7,8,10}$ Schaal and Barr performed a retrospective chart review of patients who received early vitrectomy (within 1 week), late vitrectomy (after 2 weeks), and medical management only. ${ }^{24}$ Although the visual outcome was not statistically different among the groups, the study was limited by selection bias. The patients who had early or delayed vitrectomy had a more severe clinical course than those who could be managed with medical therapy alone. ${ }^{24}$ For those patients referred a few days after the complicated cataract extraction, performance of anterior vitrectomy and insertion of posterior chamber IOL implant at the time of cataract surgery have been associated with better visual outcome. ${ }^{7,9,10}$ In this present study, the timing of vitrectomy after lens dislocation was left up to the discretion of the vitreoretinal surgeon performing the operation and was largely based on the severity of inflammation, IOP, and the degree of fundus visualization. Seventy-five percent underwent anterior vitrectomy and $91 \%$ received some form of IOL implant prior to vitrectomy. Similar to other studies, the timing of vitrectomy, whether it was on the same day as the cataract surgery or delayed, was not associated with the final visual outcome or the time to achieve BCVA. Additionally, the size of the retained nucleus did not have any effect on the healing time or the time to BCVA.

Reported postoperative complications after 20-gauge techniques include glaucoma $(2 \%-11 \%)$, retinal detachment ( $8 \%-22 \%)$, and cystoid macular edema $(12 \%-28 \%){ }^{7-9}$ Consistent with other studies, complications encountered in this present study largely depended on the preexisting posterior pathology, and were not necessarily related to the vitrectomy procedure itself. ${ }^{4,10}$ For example, there is a high rate of progression of diabetic macula edema after any intraocular procedure. Preexisting eye disease, occurrence of retinal detachment, and choroidal detachment after vitrectomy have been correlated with a poor visual outcome. ${ }^{4}$ Most of the patients in this present study had significant prior ocular pathology such as preexisting choroidal detachment, proliferative diabetic retinopathy, and/ or glaucoma. As listed in Table 3, reasons for poor final visual outcome were related to preexisting eye disease. Post-cataract extraction complications prior to vitrectomy included hyphema, vitreous hemorrhage, ocular hypertension, and central retinal vein occlusion. Vitrectomy in these cases was delayed until the eye became more stable. Morris et al has advocated the use of prophylactic laser treatment to prevent retinal detachment after removal of retained lens. ${ }^{25}$ In this present study, 360 degree laser treatments was not performed on any of the patients. A careful peripheral retinal examination using scleral depression at the end of each case obviated the need for prophylactic laser. There were no postoperative retinal detachment or tear complications.

Another concern with micro-incision sutureless vitrectomies like the 23-gauge or 25-gauge system is the increased rate of postoperative hypotony and endophthalmitis. ${ }^{27-29}$ With increased experience with sutureless vitrectomy, the rate of endophthalmitis across all gauges compared with the standard 20-gauge has become equivalent. ${ }^{2,26}$ In the present study, there were no cases of endophthalmitis. There were two cases of postoperative choroidal effusion, one of which was secondary to a complicated cataract extraction. The other one occurred despite suturing of all three sclerotomies and resolved by the first postoperative week.

Limitations of the current study include a small sample size and the retrospective nature of the study. A prospective head-to-head comparison of several gauge systems (eg, 20-, 23-, and 25-) for the management of posteriorly dislocated lens would better elucidate the difference in efficacy and safety profiles of these approaches. Nevertheless, the current study illustrates the effectiveness of the 23-gauge vitrectomy system alone or combined with the 20-gauge fragmatome for removal of posteriorly dislocated crystalline lens material. Until the 23-gauge fragmatome becomes available, the technique described in this study remains a safe and efficient option with excellent final visual outcome and low complication rate.

\section{Acknowledgments}

Support was provided by the St Giles Foundation (RVPC) and in part from a departmental grant from Research to Prevent Blindness (MC, RVPC). This paper has not been presented in any meetings. 


\section{Disclosure}

There are no financial interests or relationships to disclose in this work.

\section{References}

1. Leaming DV. Practice styles and preferences of ASCRS members 1994 survey. J Cataract Refract Surg. 1995;21(4):378-385.

2. Scott IU, Flynn HW Jr, Acar N, et al. Incidence of endophthalmitis after 20 -gauge vs 23 -gauge vs 25 -gauge pars plana vitrectomy. Graefes Arch Clin Exp Ophthalmol. 2011;249(3):377-380.

3. Kwok AKH, Li KKW, Lai TYY, Lam DSC. Pars plana vitrectomy in the management of retained intravitreal lens fragments after cataract surgery. Clin Experiment Ophthalmol. 2002;30(6):399-403.

4. Al-Khaier A, Wong D, Lois N, et al. Determinants of visual outcome after pars plana vitrectomy for posteriorly dislocated lens fragments in phacoemulsification. J Cataract Refract Surg. 2001;27(8):1199-1206.

5. Hansson LJ, Larsson J. Vitrectomy for retained lens fragments in the vitreous after phacoemulsification. J Cataract Refract Surg. 2002; 28(6):1007-1011.

6. Ho SF, Zaman A. Clinical features and outcomes of pars plana vitrectomy in patients with retained lens fragments after phacoemulsification. J Cataract Refract Surg. 2007;33(12):2106-2110.

7. Margherio RR, Margherio AR, Pendergast SD, et al. Vitrectomy for retained lens fragments after phacoemulsification. Ophthalmology. 1997;104(9):1426-1432.

8. Borne MJ, Tasman W, Regillo C, Malecha M, Sarin L. Outcomes of vitrectomy for retained lens fragments. Ophthalmology. 1996;103(6): 971-976.

9. Scott IU, Flynn HW Jr, Smiddy WE, et al. Clinical features and outcomes of pars plana vitrectomy in patients with retained lens fragments. Ophthalmology. 2003;110(8):1567-1572.

10. Ho LY, Doft BH, Wang L, Bunker CH. Clinical predictors and outcomes of pars plana vitrectomy for retained lens material after cataract extraction. Am J Ophthalmol. 2009;147(4):587-594.

11. Kadonosono K, Yamakawa T, Uchio E, Yanagi Y, Tamaki Y, Araie M. Comparison of visual function after epiretinal membrane removal by 20 -gauge and 25-gauge vitrectomy. Am J Ophthalmol. 2006; 142(3):513-515.

12. Rizzo S, Genovesi-Ebert F, Murri S, et al. 25-Gauge, sutureless vitrectomy and standard 20-gauge pars plana vitrectomy in idiopathic epiretinal membrane surgery: a comparative pilot study. Graefes Arch Clin Exp Ophthalmol. 2006;244(4):472-479.

13. Chang CJ, Chang YH, Chiang SY, Lin LT. Comparison of clear corneal phacoemulsification combined with 25 -gauge transconjunctival sutureless vitrectomy and standard 20-gauge vitrectomy for patients with cataract and vitreoretinal diseases. J Cataract Refract Surg. 2005; 31(6):1198-1207.
14. Wimpissinger B, Kellner L, Brannath W, et al. 23-Gauge versus 20 -gauge system for pars plana vitrectomy: a prospective randomised clinical trial. Br J Ophthalmol. 2008;92(11):1483-1487.

15. Keshavamurthy R, Venkatesh P, Garg S. Ultrasound biomicroscopy findings of $25 \mathrm{G}$ transconjuctival sutureless (TSV) and conventional (20G) pars plana sclerotomy in the same patient. BMC Ophthalmol. 2006;6:7.

16. Fine HF, Iranmanesh R, Iturralde D, Spaide RF. Outcomes of 77 consecutive cases of 23-gauge transconjunctival vitrectomy surgery for posterior segment disease. Ophthalmology. 2007;114(6):1197-1200.

17. Chen E. 25-gauge transconjunctival sutureless vitrectomy. Curr Opin Ophthalmol. 2005;18(3):188-193.

18. Narayanan R, Sinha A, Reddy RK, Krishnaiah S, Kuppermann BD. Faster visual recovery after 23 -gauge vitrectomy compared with 20-gauge vitrectomy. Retina. 2010;30(9):1511-1514.

19. Ho LY, Walsh MK, Hassan TS. 25-Gauge pars plana vitrectomy for retained lens fragments. Retina. 2010;30(6):843-849.

20. Kongsap P. Combined 20-gauge and 23-gauge pars plana vitrectomy for the management of posteriorly dislocated lens: a case series. Clin Ophthalmol. 2010;4:625-628.

21. Fujii GY, De Juan E Jr, Humayun MS, et al. A new 25-gauge instrument system for transconjunctival sutureless vitrectomy surgery. Ophthalmology. 2002;109(10):1807-1813.

22. Chieh JJ, Rogers AH, Wiegand TW, Baumal CR, Reichel E, Duker JS. Short-term safety of 23-gauge single-step transconjunctival vitrectomy surgery. Retina. 2009;29(10):1486-1490.

23. Nagpal M, Wartikar S, Nagpal K. Comparison of clinical outcomes and wound dynamics of sclerotomy ports of 20,25, and 23 gauge vitrectomy. Retina. 2009;29(2):225-231.

24. Schaal S, Barr CC. Management of retained lens fragments after cataract surgery with and without pars plana vitrectomy. J Cataract Refract Surg. 2009;35(5):863-867.

25. Morris RE, Shere JL, Witherspoon CD, et al. Intraoperative retinal detachment prophylaxis in vitrectomy for retained cataract fragments. $J$ Cataract Refract Surg. 2009;35(3):491-495.

26. Kunimoto DY, Kaiser RS; for the Wills Eye Retina Service. Incidence of endophathalmitis after 20- and 25-gauge virectomy. Ophthalmology. 2007;114(12):2133-2137.

27. Gupta OP, Weichel ED, Regillo CD, et al. Postoperative complications associated with 25-gauge pars plana viterectomy. Ophthalmic Surg Laser Imaging. 2007;38(4):270-275.

28. Scott IU, Flynn HW Jr, Dev S, et al. Endophthalmitis after 25-gauge and 20-gauge pars plana vitrectomy: incidence and outcomes. Retina. 2008;28(1):138-142.

29. Parolini B, Romanelli F, Prigione G, Pertile G. Incidence of endophthalmitis in a large series of 23-gauge and 20-gauge transconjunctival pars plana vitrectomy. Graefes Arch Clin Exp Ophthalmol. 2009; 247(7):895-898.
Clinical Ophthalmology

\section{Publish your work in this journal}

Clinical Ophthalmology is an international, peer-reviewed journal covering all subspecialties within ophthalmology. Key topics include: Optometry; Visual science; Pharmacology and drug therapy in eye diseases; Basic Sciences; Primary and Secondary eye care; Patient Safety and Quality of Care Improvements. This journal is indexed on Submit your manuscript here: http://www.dovepress.com/clinical-ophthalmology-journal

\section{Dovepress}

PubMed Central and CAS, and is the official journal of The Society of Clinical Ophthalmology (SCO). The manuscript management system is completely online and includes a very quick and fair peer-review system, which is all easy to use. Visit http://www.dovepress.com/ testimonials.php to read real quotes from published authors. 